\title{
Effect of hyaluronic acid on osteoblast function in vivo and on fracture healing in an experimental rabbit model
}

\author{
xiang Li \\ Lanzhou University \\ Ruimin Xie \\ Lanzhou University
}

xiong Wang

First Hospital of Lanzhou University

bohua Li

First Hospital of Lanzhou university

Yongping Wang ( $\triangle$ wangyp2019@163.com )

Lanzhou University First Affiliated Hospital https://orcid.org/0000-0001-8219-7748

Research article

Keywords: fracture; fracture healing; hyaluronic acid; cell culture; animal model

Posted Date: October 22nd, 2019

DOI: https://doi.org/10.21203/rs.2.16349/v1

License: (c) (1) This work is licensed under a Creative Commons Attribution 4.0 International License. Read Full License 


\section{Abstract}

Background: Fracture healing is regulated by endocrine hormones and biochemical and biophysical factors, including hyaluronic acid (HA), which is a component of the extracellular matrix. The prerequisites for biological responses that promote fracture healing, such as biomechanical conditions, and molecular factors, can be investigated in bone cell cultures. Methods: In this study, HA promoted the formation of calcium nodules and the expression of runt-related transcription factor (Runx) 2 and osteocalcin (OCN) proteins in MC3T3-E1 cells. Results: In a rabbit tibial fracture model, HA promoted formation of larger calluses than those in control or sham-treated animals at $2,4,6$, and 8 weeks $(P<$ 0.05). Osteophytes were larger in HA-treated than in control animals at 4 and 6 weeks $(P<0.05)$. Bone mineral density was greater in HA-treated than in control animals at 4,6 , and 8 weeks $(P<0.05)$. Conclusions: The results showed that HA promoted the formation of calcified nodules in bone cell cultures and healing of rabbit tibial fractures.

\section{Background}

Fracture healing is regulated by endocrine hormones, biochemical, and biophysical factors. The prerequisites of good biological responses promoting fracture healing, including biomechanical conditions, and molecular factors, can be investigated in bone cell line cultures. Hyaluronic acid (HA) is a polysaccharide polymer present in the extracellular matrix of vertebrate connective tissue, and was first

isolated from bovine vitreous humor ${ }^{[1,2]}$. HA is composed of repeating disaccharide units of D-glucuronic acid (GICA) and N-acetyl-D-glucosamine (GICNAc), with formation of glycosidic bonds catalyzed by hyaluronan synthases ${ }^{[3]}$. It has broad medical applications, including relief from osteoarthritis pain and improving joint function because it is biocompatible, hydrophilic, absorbable, and has anti-inflammatory activity ${ }^{[4]}$. HA supports cell proliferation and differentiation in temporary scaffolds used to promote the growth and calcification of osteoblasts and new bone formation ${ }^{[6]}$. There is extensive evidence of the effects of HA on osteoblasts. Injection of 5,000 kDa high molecular weight HA into the maxilla and mandibula of rats resulted in a significant increase in the osteoblasts present in the jaws and premaxillary suture ${ }^{[7]}$. Sá found that low concentrations of $\mathrm{HA}(1,10$, and $100 \mathrm{ng} / \mathrm{mL})$ had no effect on osteoblast activity but reported that methylthiazolyl tetrazolium bromide (MTT) and immunofluorescence assays found that a high concentration $(1 \mathrm{~g} / \mathrm{L})$ for $48 \mathrm{~h}$ decreased osteoblast viability ${ }^{[9]}$. Von Kossa calcium staining of osteoblast cultures showed that $100 \mathrm{ng} / \mathrm{mL}$ HA significantly increased the area of nodule formation and RT-PCR confirmed that that HA was associated with type I and III collagen, osteocalcin, and bone morphogenetic protein 2 and 4 expression ${ }^{[11]}$. Injection of $1 \% \mathrm{HA}$ into the alveolar fossa after tooth extraction was found to increase the deposition of mineralized bone and osteoblast number ${ }^{[8]}$. Another study found that HA did not influence cell proliferation, but alizarin red staining confirmed that it induced osteoblast differentiation. Formation of mineralized nodules increased with the expression of osteocalcin mRNA and the number of calcium nodules formed by osteoblasts increased with the increase of the molecular weight of $\mathrm{HA}^{[10,12]}$. Other studies have confirmed the effect of $\mathrm{HA}$ on cell viability by an oxygen consumption assay and increased expression of type I collagen and 
osteonectin by immunohistochemistry ${ }^{[13]}$. In an inflammation model induced by interleukin-1, HA increased metalloproteinase 3 and matrix metalloproteinase 13 expression and reduced the expression of ADAMTS-4 and -5, RANKL, CD44, and the intercellular adhesion molecule (ICAM)-1 gene ${ }^{[14]}$. Boeckel reported that HA did not have a significant effect on osteoblast viability as asayed by MTT ${ }^{[15]}$.

This study investigated the effects of HA on the growth and differentiation of osteoblasts and promotion of fracture healing. The effect of HA on the proliferation of MC3T3-E1 cells was assayed by CCK-8 and alizarin red, formation of calcium nodules and expression of Runx2 and OCN proteins was assayed by immunoblotting. Bone histomorphometry was investigated by X-ray in a rabbit model of tibial fracture.

\section{Material And Methods}

Test cells: MC3T3-E1 cell line, purchased from Shanghai Zhongzhou Biotechnology Co., Ltd..

Test animals: New Zealand white rabbits, purchased from Lanzhou Veterinary Research Institute, Chinese Academy of Agricultural Sciences.

\subsection{Cell culture}

MC3T3-E1 cells were cultured in a high glucose Dulbecco's Modified Eagle's Medium (DMEM) containing $10 \%$ fetal bovine serum at $37^{\circ} \mathrm{C}, 95 \%$ relative humidity, and $5 \% \mathrm{CO}_{2}$. The cells were passaged every $3-4$ days at 1:3. After two-four passages, osteoblasts in logarithmic growth phase were used in the experimental procedures.

\subsection{Cell proliferation}

A $1 \mathrm{~mL}$ suspension of $2 \times 10^{7} \mathrm{~L}^{-1}$ MC3T3-E1 cells was added to each well of a 24 -well plate and $0.125 \mu \mathrm{g} /$ $\mu \mathrm{L}, 0.25 \mu \mathrm{g} / \mu \mathrm{L}, 0.5 \mu \mathrm{g} / \mu \mathrm{L}$, or $1 \mu \mathrm{g} / \mu \mathrm{L}$ HA in high-dose DMEM containing $10 \%$ fetal bovine serum was added. An equal volume of medium alone was added to control wells. The plates were incubated at $37^{\circ} \mathrm{C}$, $95 \%$ relative humidity, and $5 \% \mathrm{CO}_{2}$ with a change in medium every 2 days. The cells were collected by trypsinization on day 1,5 , or 7 , suspended in $1 \mathrm{~mL}$ high glucose DMEM containing $10 \%$ fetal bovine serum, and seeded in 96-well culture plates at $200 \mu \mathrm{L}$ well with six wells per sample. After culture for $24 \mathrm{~h}$, $10 \mu \mathrm{L}$ CCK-8 was added and the absorbance was measured at $450 \mathrm{~nm}$ using a microplate reader after incubation for $30 \mathrm{~min}$.

\subsection{Western blot assays}

Total protein was isolated from MC3T3-E1 cells before and after HA treatment and 15-20 $\mu \mathrm{L}$ samples were separated on $10 \mathrm{~cm} \times 10 \mathrm{~cm}$ gels by sodium dodecyl sulfate polyacrylamide gel electrophoresis (SDS-PAGE). The proteins were transferred by blotting onto membranes for immunological hybridization with anti-runt-related transcription factor 2 (Runx2) and anti-osteocalcin $(\mathrm{OCN})$ primary antibodies and 
color development. The expression of Runx2 and OCN proteins in MC3T3-E1 cells before and after HA treatment were compared.

\subsection{Mineralization of MC3T3-E1 cells}

A $1 \mathrm{~mL}$ suspension of $2 \times 10^{7} \mathrm{~L}^{-1}$ MC3T3-E1 cells in high sugar DMEM was added to each well of a 24well plate. HA in DMEM with $10 \%$ fetal bovine serum, $0.05 \mathrm{mmol} \cdot \mathrm{L}^{-1}$ ascorbic acid, and $10 \mathrm{mmol} \beta-$ glycerol was added. The plates were cultured at $37^{\circ} \mathrm{C}, 95 \%$ relative humidity and $5 \% \mathrm{CO}_{2}$ and the culture medium was changed every 3 days. After 21 days of culture and appearance of milky white spots, culture medium containing $50 \mathrm{mg} / \mathrm{L}$ alizarin red was added for $30 \mathrm{~min}$. Cultures were then rinsed three times with phosphate-buffered saline, and then fixed with a volume fraction of $95 \%$ ethanol for $10 \mathrm{~min}$.

\subsection{Animal model}

The institutional Ethics Committee approved the study. Eighty adult male white New Zealand rabbits 810 months of age and weighing 2,000-3,000 g were used and were handled following the Ethics Committee guidelines for the use of animals in experimental studies. Forty-eight rabbits were randomly divided into experimental, control, and sham operation groups of 16 each. After anesthesia induced by intravenous injection of $50 \mathrm{mg} / \mathrm{kg}$ sodium pentobarbital, the left rear leg was shaved, the skin was disinfected and surgically opened. The subcutaneous tissue was dissected to expose the tibia and an incomplete transverse fracture as made in the middle tibia with pendulum saw. The fracture width was about $2 \mathrm{~mm}$ and the depth was about one-third of the tibia diameter. The wound was sutured and penicillin was injected intramuscularly for 3 days after surgery to prevent infection (Fig. 1).

Rabbits in the experimental group were given a single $0.2 \mathrm{~mL} H A$ injection into the fracture region on the first day after surgery. Those in the control group were given normal saline, and sham operation rabbits were not given any treatment after surgery. Two, 4, 6, and 8 weeks after surgery, four rabbits in each group were randomly selected, anesthetized with $1 \%$ pentobarbital and sacrificed for evaluation of bone healing on X-ray films and bone histomorphometry.

All experimental animals were given an excessive intraperitoneal injection of pentobarbital to prevent pain and sudden death in rabbits, which was not ethical. The rabbits after the death were incinerated by the Animal Experimental Center of Lanzhou University.

\subsection{Statistical analysis}

The statistical analysis was performed with SPSS 10.0. Differences in general condition (wound oozing, redness and infection, daily feed consumption, activity level, and behavior) and histological findings (bony area and width of the epiphysis, and percentage of osteoid tissue) were compared. The pairedsample $t$-test was used for within-group comparisons. The independent $t$-tests was used for betweengroup comparisons. The significance level was $P<0.05$. 


\section{Results}

3.1. Proliferation of MC3T3-E1 cells

When added to cultures of MC3T3-E1 cells at concentrations of $0.125,0.25,0.5$, or $1 \mu \mathrm{g} / \mu \mathrm{L}, \mathrm{HA}$ had no significant effect on proliferation ( $P>0.05$ ) after either 36 or $72 \mathrm{~h}$ of incubation. (Fig. 2).

\section{2 formation of calcium nodules in MC3T3-E1-cell cultures}

Alizarin red staining after 28 days of cell culture with $1 \mu \mathrm{g} / \mu \mathrm{L}$ HA revealed large numbers of calcified nodules. Mostly were round or elliptical, a few were irregular. Fewer nodules were seen in the control cultures (Fig. 3). Comparison of six randomly selected fields in each well for each treatment found that the area of the mineralized nodules in was significantly larger in HA-treated than in control cultures $(P<$ 0.05, Fig. 3).

A:Formation of MC3T3-E1 mineralized nodules under optical microscope;B:Mineralized nodule area relative to control group after $\mathrm{HA}$ intervention

\subsection{Expression of Runx2 and OCN proteins in MC3T3-E1 cells}

Western blot results showed that both Runx 2 and OCN expression were upregulated by the induction medium and were further upregulated after adding HA. Protein expression was the highest at $1 \mu \mathrm{g} / \mu \mathrm{L} \mathrm{HA}$ and was significantly higher at that concentration than it was in the control group. $(P<0.05$, Fig. 4$)$

\subsection{Animal model}

All 48 New Zealand rabbits were successfully modeled. No rabbits died, but their activity and food consumption decreased, and their mental state was impaired for at least 1-3 days. Rabbits in the sham operation group returned to normal after 4 days. Those in the experimental group returned to normal after 1 week. Animals in the control group were less active than those in the other two groups for 2 weeks. Most rabbits appeared healthy, but those in the sham operation, control, and experimental groups remained lame for about 1 month. Half the rabbits developed edema in the lower extremities that resolved within 2 weeks. One of the two rabbits that developed infections died.

\subsection{Evaluation of fracture healing}

X-ray films of rabbits in the control group at 2 weeks after surgery showed a sharp fracture edge, mildly reactive periosteum, a clear fracture line, discontinuous cortical bone, and swelling of the surrounding soft tissue. In the experimental group, the appearance of the fracture edge, periosteal cortical bone were similar to controls. The fracture line was clear but slightly blurred compared with the control group. There less swelling of the surrounding soft tissue than in the control rabbits (Fig. 5). 
In X-ray films of control group rabbits 4 weeks after surgery, the fracture edge was not clear, the size of the callus had increased, the fracture line was blurred, the cortical bone was discontinuous, and the surrounding soft tissue shadow persisted. In the experimental group animals, the fracture edge was also blurred, with increased callus formation and discontinuous cortical bone, but the fracture end bone density was higher and the surrounding soft tissue shadow was reduced compared with control group rabbits (Fig. 6).

In X-ray films 6 weeks after surgery, the fracture edge in control group rabbits was blurred, and a small external epiphysis surrounded the fracture. The edge of the epiphysis was blurred, the fracture line was visible, and the cortical bone was discontinuous. The bone on either side of the fracture was more dense In the experimental than in the control rabbits and the fracture line was blurred (Fig. 7)

At 8 weeks after surgery, the fracture edge of the control group was blurred, the external epiphysis surrounded the fracture, the edge of the epiphysis was clean, and the fracture line was visible but fuzzy. The cortical bone was discontinuous. The bone density and blurring were greater in the rabbits in the experimental group compared with the control animals and the fracture line was nearly invisible. (Fig. 8)

Bone histomorphometry included measuring the total area of the epiphysis on lateral radiographs at 2, 4, 6 , and 8 weeks after fracture. The osteophyte area was greater in the experimental than in the control rabbits at 2, 4, and 6 weeks, but the difference was no longer significant at 8 weeks because of increased size in the control group (Tables $1-3$ and Figs 9,10).

Table.1 bone metrology parameters in experimental group and control group after 2 week $\square$ n=6ロ

\begin{tabular}{|c|c|c|c|}
\hline parameter & Control group & test group & $\mathrm{P}$ value \\
\hline Bone-like area $\llbracket \mathrm{mm} 2 \square$ & $71.48 \pm 8.03$ & $112.36 \pm 6.52$ & $P \square 0.05$ \\
\hline Bone-like width $\llbracket \mathrm{mm} \rrbracket$ & $6.08 \pm 0.39$ & $6.14 \pm 0.14$ & $P \sqcap 0.05$ \\
\hline Perioid percentage $₫ \%$ & $2.51 \pm 0.30$ & $2.94 \pm 0.61$ & $P \square 0.05$ \\
\hline
\end{tabular}


Table.2 bone metrology parameters in experimental group and control group after 4 week $\square \mathrm{n}=6 \square$

\begin{tabular}{|c|c|c|c|}
\hline parameter & Control group & test group & $\mathrm{P}$ value \\
\hline Bone-like area $\square \mathrm{mm} 2 \square$ & $93.25 \pm 6.61$ & $158.10 \pm 9.64$ & $P \sqcap 0.05$ \\
\hline Bone-like width $\square \mathrm{mm} \square$ & $7.13 \pm 0.44$ & $7.27 \pm 0.31$ & $P \sqcap 0.05$ \\
\hline Perioid percentage $\square \% \square$ & $2.85 \pm 0.40$ & $10.01 \pm 0.70$ & $P \square 0.05$ \\
\hline
\end{tabular}

Table.3 bone metrology parameters in experimental group and control group after 6 week $\square n=6 \square$

\begin{tabular}{|c|c|c|c|}
\hline parameter & Control group & test group & $\mathrm{P}$ value \\
\hline Bone-like area $₫ \mathrm{~mm} 2 \square$ & $173 \pm 4.71$ & $179 \pm 8.36$ & $P \sqcap 0.05$ \\
\hline Bone-like width $\llbracket \mathrm{mm} \rrbracket$ & $4.93 \pm 0.35$ & $5.04 \pm 0.42$ & $P \square 0.05$ \\
\hline Perioid percentage $₫ \square \square$ & $2.18 \pm 0.63$ & $2.37 \pm 0.36$ & $P \square 0.05$ \\
\hline
\end{tabular}

\section{Discussion}

The molecular formula of $\mathrm{HA}$ is $\left(\mathrm{C}_{14} \mathrm{H}_{21} \mathrm{NO}_{11}\right) \mathrm{n}$; the structural formula is shown in Fig. 11. It is a linear polysaccharide composed of a repeating linkage of GlcA and GIcNAc by

$\beta$-glycosidic bonds. It has a negative charge and is present in the connective tissue of vertebrates. Unlike other glycosaminoglycans (GAGs) in connective tissue, $\mathrm{HA}$ is synthesized in the plasma membrane rather than the endoplasmic reticulum or Golgi body. It contains no peptides, is not linked to a core protein, is not sulfated, and has not undergone any postsynthesis modification. Like other GAGs, HA consists of a single polysaccharide chain that can have a molecular weight in the millions. Secondary hydrogen bonds that form along the axis give HA a rigid spiral columnar structure that is nonpolar and hydrophobic. The surface of the column includes hydroxyl groups with strong hydrophilicity. It structure gives HA excellent rheological properties, lubricity, permeability, and water retention. When hydrated, $\mathrm{HA}$ is viscoelastic ${ }^{[5]}$. HA has great potential for medical applications. 
Previous studies have described the effects of HA on cell adhesion and migration, angiogenesis, morphogenesis, wound healing, inflammatory responses, and cancer metastasis. Preclinical studies of HA in orthopedics have included treatment of osteoarthritis, cartilage tissue engineering, and studies of bone morphogenetic protein carriers. Kim described the use of HA acrylate-based hydrogels as tissue engineering scaffolds to carry seed cells and active molecules to induce bone formation ${ }^{[16]}$. Tissue engineering has achieved good early results in the repair of cartilage tissue. The use of stents to implant specific cell types and bioactive molecules has also been described ${ }^{[17]}$. Martínez-Sanz described the preparation and use of noncytotoxic crosslinked aldehyde- and hydrazide-modified HA gels for controlled release of bone molecular protein (BMP)-2 ${ }^{[18]}$. In a rat calvarium model of bone formation, the hydrogels induced formation of new bone and increased osteocalcin and osteopontin expression. Bone cement composed of nanocrystalline hydroxyapatite crosslinked to an HA-tyramine conjugate was found to have a low heat release compared with conventional bone cement, produced little damage of surrounding tissues, and successfully repaired small bone and joint defects in mice ${ }^{[19]}$. Exogenous HA oligosaccharides were reported to significantly inhibit growth of LM-8 and MG-63 osteosarcoma cells ${ }^{[20]}$.

Traumatic injury including severe fractures are increasingly common, and while treatment outcomes are generally favorable, $5 \%-10 \%$ of patients experience fracture nonunion ${ }^{[21]}$. Previous studies have not reported the promotion of fracture healing by HA in an animal model. Effective promotion of callus formation, acceleration of fracture healing and overall patient healing are primary goals in orthopedic practice. HA did not significantly influence MC3T3-E1 cell proliferation, but it did promote the formation of mineralized nodules that was associated with increased Runx2 and OCN expression.

\section{Conclusions}

HA accelerated fracture healing by promoting the formation of osteophytes and relieving soft tissue swelling. It had a positive effect on the growth of osteoblasts, which is essential for bone healing.

\section{Abbreviations}

HA: Hyaluronic acid

OCN: Osteocalcin

GlcA: D-glucuronic acid

GIcNAc: N-acetyl-D-glucosamine

MTT: Methylthiazolyl tetrazolium bromide

GAGs: Glycosaminoglycans

DMEM: Dulbecco's Modified Eagle's Medium 


\section{Declarations}

\section{Acknowledgement}

The author wishes to thank the radiologist who contributed to the research and the laboratory teacher of Gansu University of Traditional Chinese Medicine.

\section{Funding}

This research was funded by Lanzhou Science and Technology Plan Project (Grant NO: 2017-4-58), Lanzhou Chengguan District Science and Technology Plan Project Fund (Grant NO: 2018-1-2), Gansu Provincial Higher Education Research Project (Grant NO: 2018B) -013), Lanzhou University First Hospital Research Project (Grant NO: Idyyyn2017-21, Idyyyn2018-47) funded.

\section{Author information}

\section{Affiliations}

Department of orthopedics, First Hospital of Lanzhou University \Lanzhou 730000®Gansu Province China.

Xiang Li , Ruimin Xie, Xiong Wang , Bohua LI, Yongping Wang

Corresponding author

Correspondence toखYongping Wang

\section{Authors' contributions}

Yongping Wang is the experiment designer and is responsible for experimenting with the entire project; critically modifying the manuscript of important knowledge content. Xiang Li: Participate in cell experiments, preparation of animal models; implementation of animal experiments; data collection; analysis and interpretation of data; statistical analysis; final approval of the version to be published. Ruimin Xie: Learning Concepts and Design; Preparation of Animal Models; Statistical Analysis; Drafting of Manuscripts; final approval of the version to be published. Xiong Wang: Preparation of animal models; data collection; final approval of the version to be published. Bohua LI: Data analysis and interpretation; final approval of the version to be published. All authors read and approved the final manuscript.

\section{Availability of data and materials}

All data generated or analysed during this study are included in this published article and its supplementary information files.

\section{Ethics approval and consent to participate}


Ethics approval and consent to participate

The study was approved by Lanzhou University First Hospital Ethics Committee No. LDYYLL2019-219, and informed written consent was obtained.

\section{Consent to publish}

Not applicable.

\section{Competing interests}

The authors declare that they have no competing interests.

\section{References}

[1].Laurent TC, Fraser JR. Hyaluronan. FASEB journal : official publication of the Federation of American Societies for Experimental Biology. 1992,6(7):2397-404.

[2].Meyer K, Palmer JW. The polysaccharide of the vitreous humor. Journal of Biological Chemistry, 1934,107(3):629-34.

[3].Furlan S, La Penna G, Perico A, Cesaro A. Hyaluronan chain conformation and dynamics.

Carbohydrate research. 2005,340(5):959-70.

[4].Noble PW. Hyaluronan and its catabolic products in tissue injury and repair. Matrix biology : journal of the International Society for Matrix Biology. 2002,21(1):25-9.

[5].Fraser J, Laurent T, Laurent U. Hyaluronan: its nature, distribution, functions and turnover. J Intern Med. 1997,242(1):27-33.

[6].Boeckel DG, Shinkai RS, Grossi ML, Teixeira ER. In vitro evaluation of cytotoxicity of hyaluronic acid as an extracellular matrix on OFCOL II cells by the MTT assay[J]. Oral surgery, oral medicine, oral pathology and oral radiology. 2014,117(6):e423-8.

[7].Cui N, Qian J, Liu T, et al. Hyaluronic acid hydrogel scaffolds with a triple degradation behavior for bone tissue engineering.Carbohydrate polymers. 2015,126:192-8.

[8].Cui N, Qian J, Xu W, et al. Preparation, characterization, and biocompatibility evaluation of poly(Nvarepsilon-acryloyl-L-lysine)/hyaluronic acid interpenetrating network hydrogels. Carbohydrate polymers. 2016,136:1017-26.

[9].Sa MA, Ribeiro HJ, Valverde TM, et al. Single-walled carbon nanotubes functionalized with sodium hyaluronate enhance bone mineralization. Brazilian journal of medical and biological research. 2016,49(2):e4888. 
[10].Jing J, Fournier A, Szarpak-Jankowska A, Block MR, Auzely-Velty R. Type, density, and presentation of grafted adhesion peptides on polysaccharide-based hydrogels control preosteoblast behavior and differentiation. Biomacromolecules. 2015,16(3):715-22.

[11].Fujioka-Kobayashi M, Schaller B, Kobayashi E,et al. Hyaluronic acid gel-based scaffolds as potential carrier for growth factors: an in vitro bioassay on its osteogenic potential. Journal of clinical medicine. 2016,5(12).

[12].Wu AT, Aoki T, Sakoda M, Ohta S, Ichimura S, Ito T, et al. Enhancing osteogenic differentiation of MC3T3-E1 cells by immobilizing inorganic polyphosphate onto hyaluronic acid hydrogel. Biomacromolecules. 2015,16(1):166-73.

[13].Mermerkaya MU, Doral MN, Karaaslan F, Huri G, Karacavus S, Kaymaz B, et al. Scintigraphic evaluation of the osteoblastic activity of rabbit tibial defects after HYAFF11 membrane application. Journal of orthopaedic surgery and research. 2016,11(1):57.

[14].Picke AK, Salbach-Hirsch J, Hintze V, Rother S, Rauner M, Kascholke C, et al. Sulfated hyaluronan improves bone regeneration of diabetic rats by binding sclerostin and enhancing osteoblast function. Biomaterials. 2016,96:11-23.

[15].Mathews S, Mathew SA, Gupta PK, Bhonde R, Totey S. Glycosaminoglycans enhance osteoblast differentiation of bone marrow derived human mesenchymal stem cells. Journal of tissue engineering and regenerative medicine. 2014,8(2):143-52.

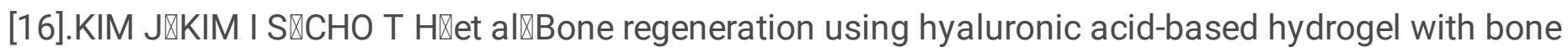
morphogenic protein-2 and human mesenchymal stem cells.Biomaterials,2007,28(10)凶1830-1837.

[17].DAHER R J, CHAHINE N 0, GREENBERG A S, et al. New methods to diagnose and treat cartilage degeneration. NAT REW Rheumatol, 2009, 5(1):599-607.

[18].MARTINEZ-SANI E, OSSIPOV DA, HILBORN J, et al. Bone reservoir: Injectable hyaluronic acid hydrogel for minimal invasive bone augmentation. J Controlled Release, 2011, 152(2):232-240.

[19].PEK YS, KURISAWA M, GAO S, et al. The deveolpment of a nanocrystalline apatite reinforced crosslinked hyaluronic acid-ty-ramine composite as an injecable bone cement. Biomaterials, 2009, 30(5):822-828.

[20].HOSONO K, NISHIDA Y, KNUDSOW W,et al. Hyaluronan oligosaccharides inhibit tumorigenicity of osteosarcoma cell lines MG-3 and LM-8 in vitro and in vivo via perturbation of hyaluronan-rich pericellular matrix of the cells. Am J Pathol, 2007, 171(1):274-286.

[21].Einhorn TA. Enhancement of freature-healing. J Bone Joint Surg Am, 1995, 77: 940-956. 
Figures
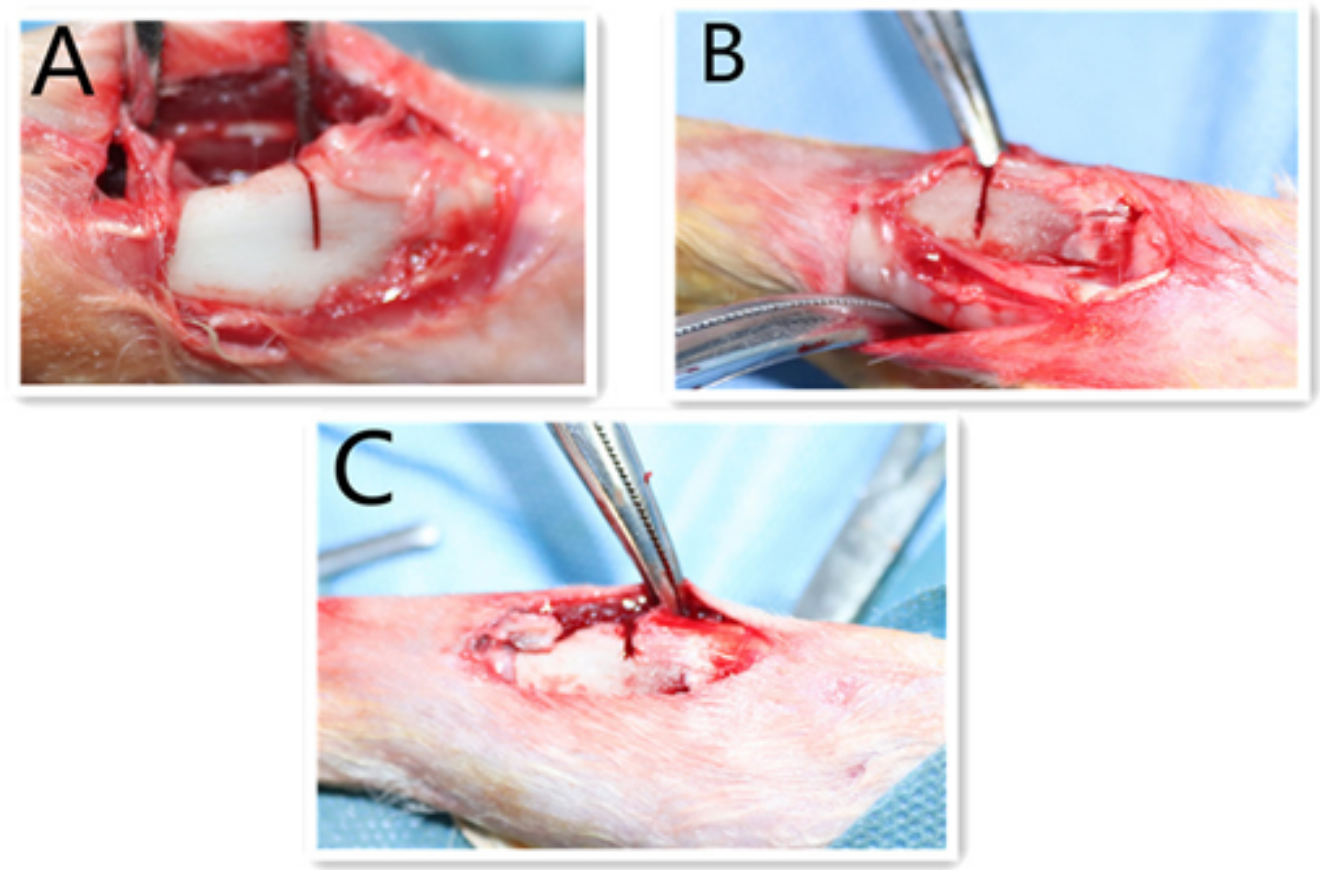

\section{Figure 1}

New Zealand rabbit tibia fracture model. (A) experimental, (B) control, and (C) sham groups.
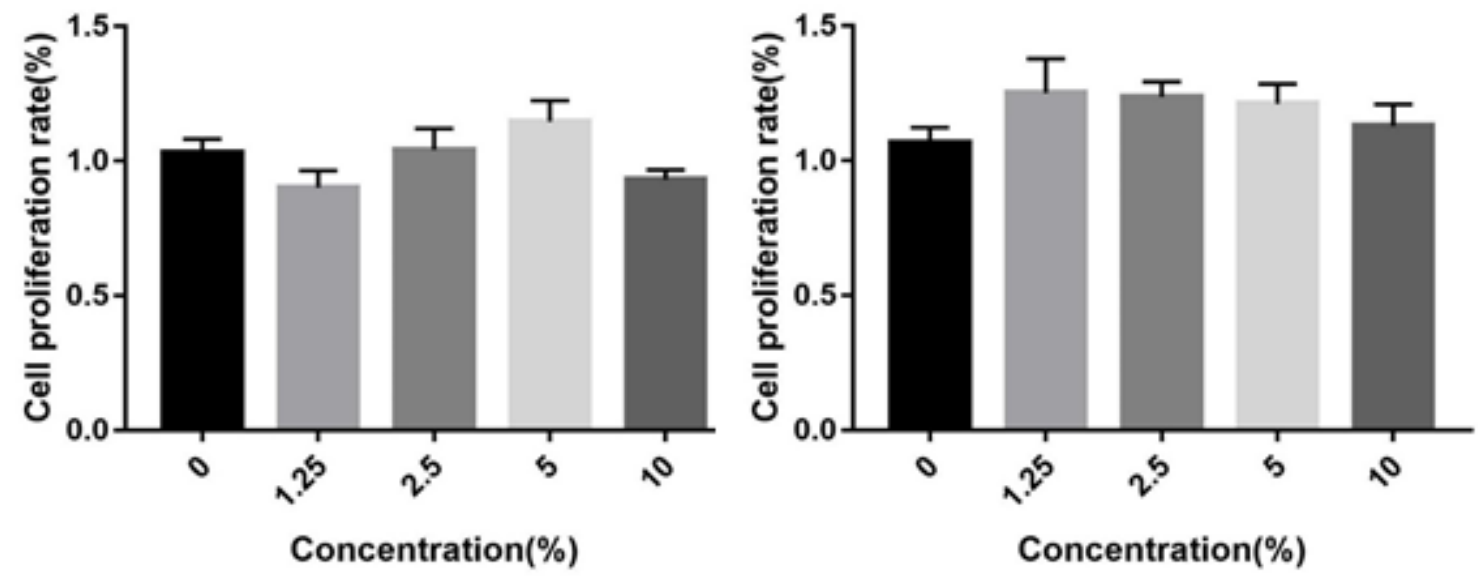

Figure 2

(A) Effect of HA intervention on the proliferation of MC3T3-E1 cells after $36 \mathrm{~h}$ and (B) after $72 \mathrm{~h}$. 

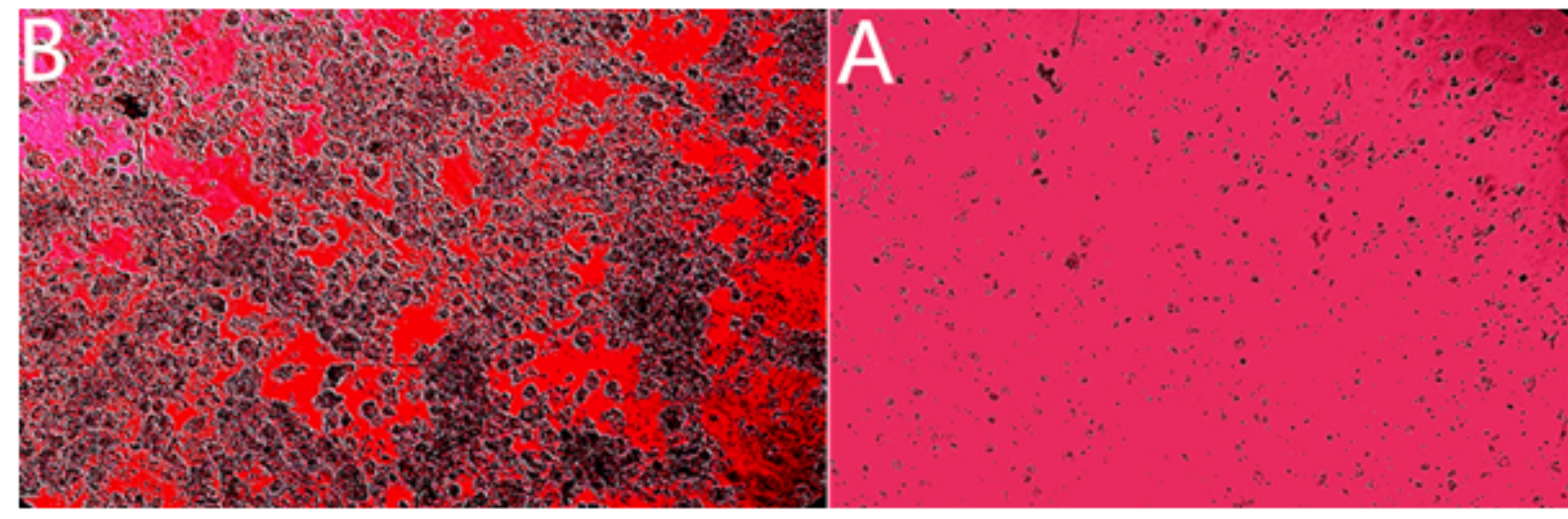

A:Formation of MC3T3-E1 mineralized nodules under optical microscope;B:Mineralized nodule area relative to control group after HA intervention

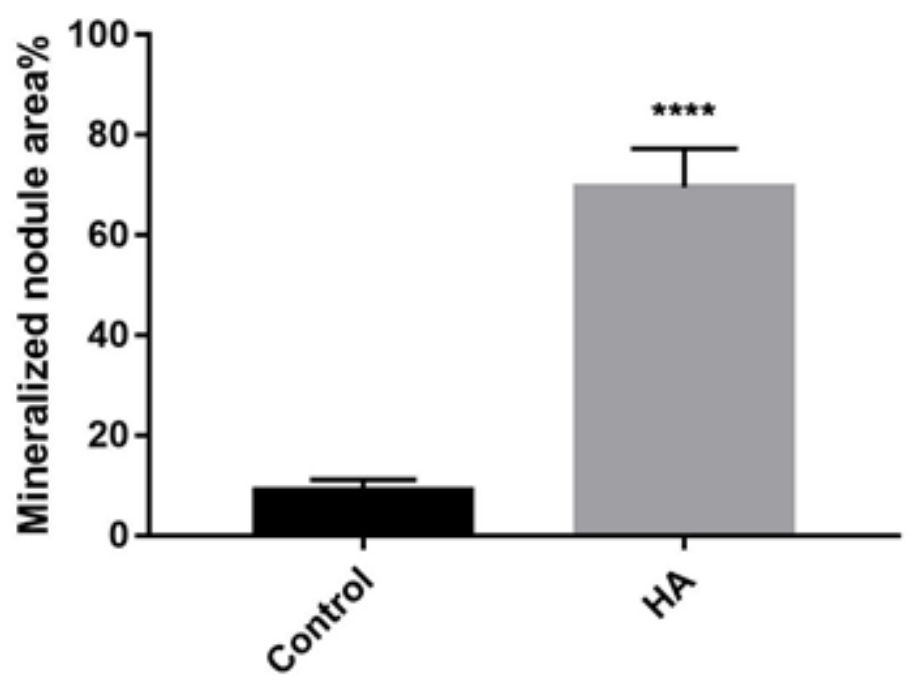

Figure 3

Formation of MC3T3-E1 mineralized nodules under optical microscope;B:Mineralized nodule area relative to control group after HA intervention

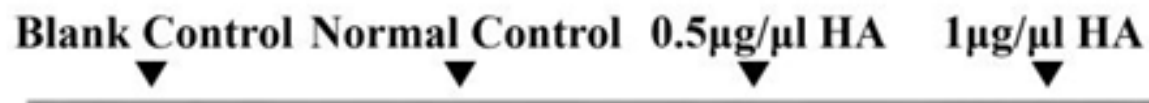

Runx 2

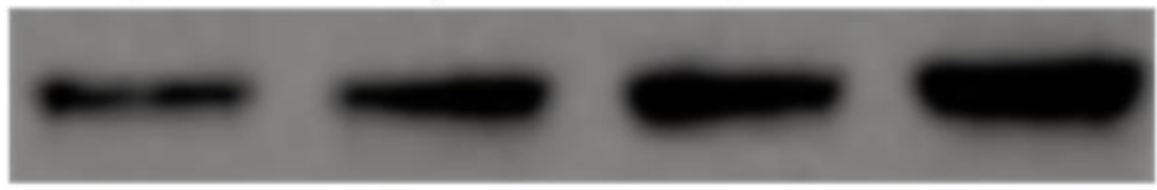

OCN

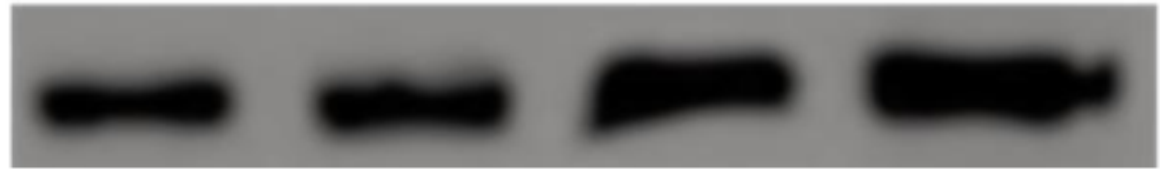

Figure 4 
Effect of HA combined with the induction medium on Runx 2 and OCN protein expression in MC3T3-E1 cells.
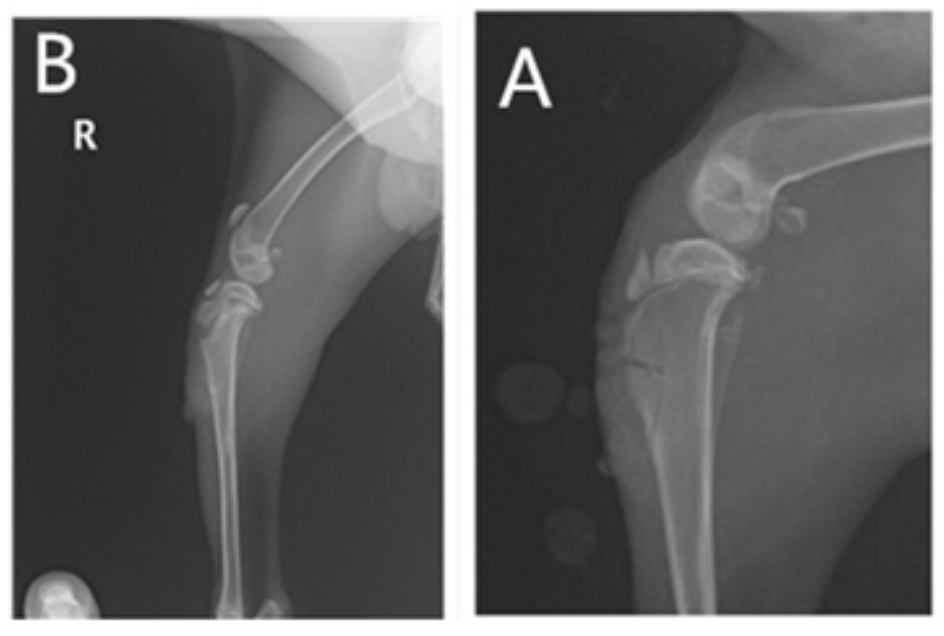

Figure 5

X-ray films 2 weeks after surgery in the (A) experimenta and (B) control groups.
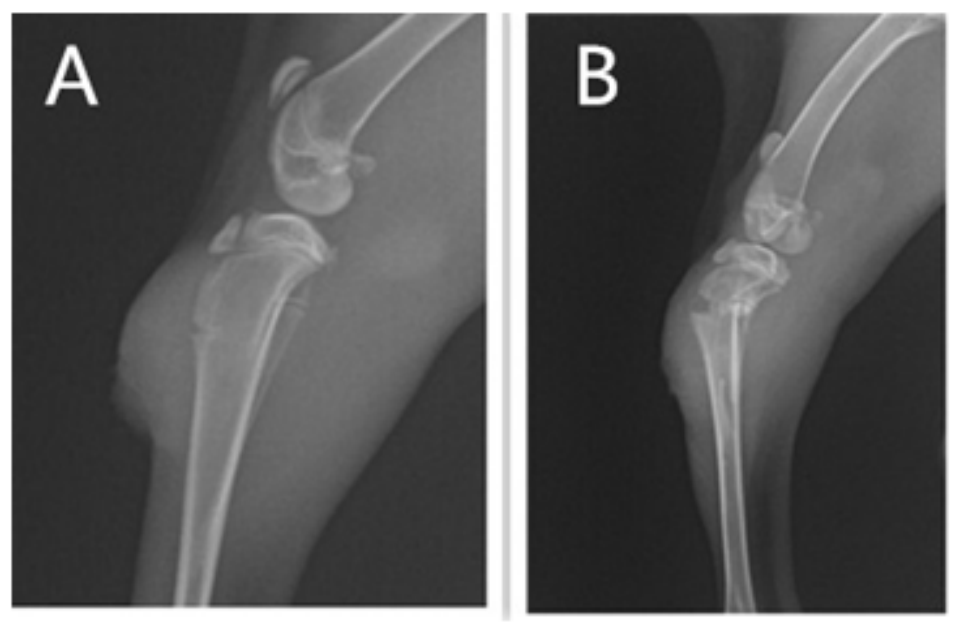

\section{Figure 6}

X-ray films 4 weeks after surgery in the (A) experimental and (B) control groups.
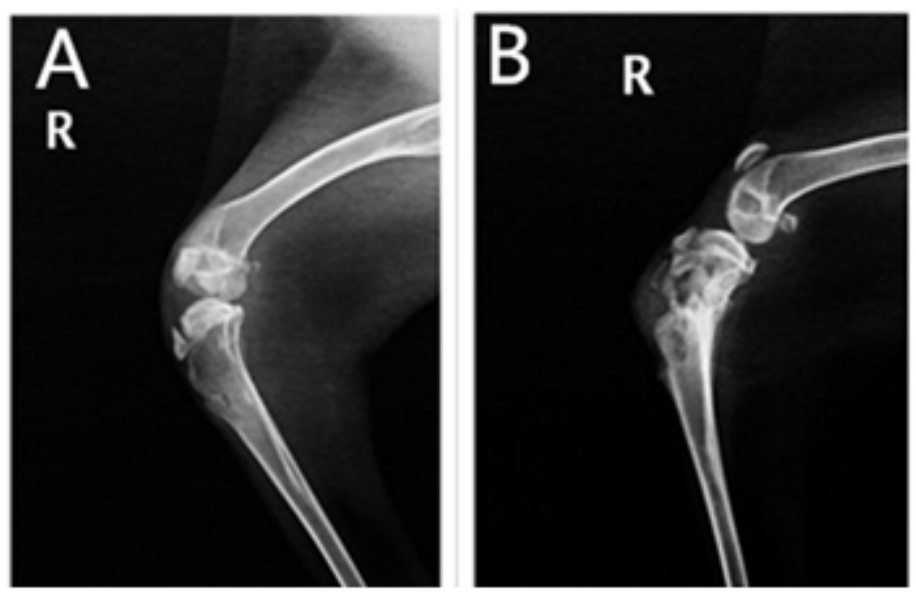
Figure 7

X-ray films 6 weeks after surgery in the (A) experimental and (B) control groups.
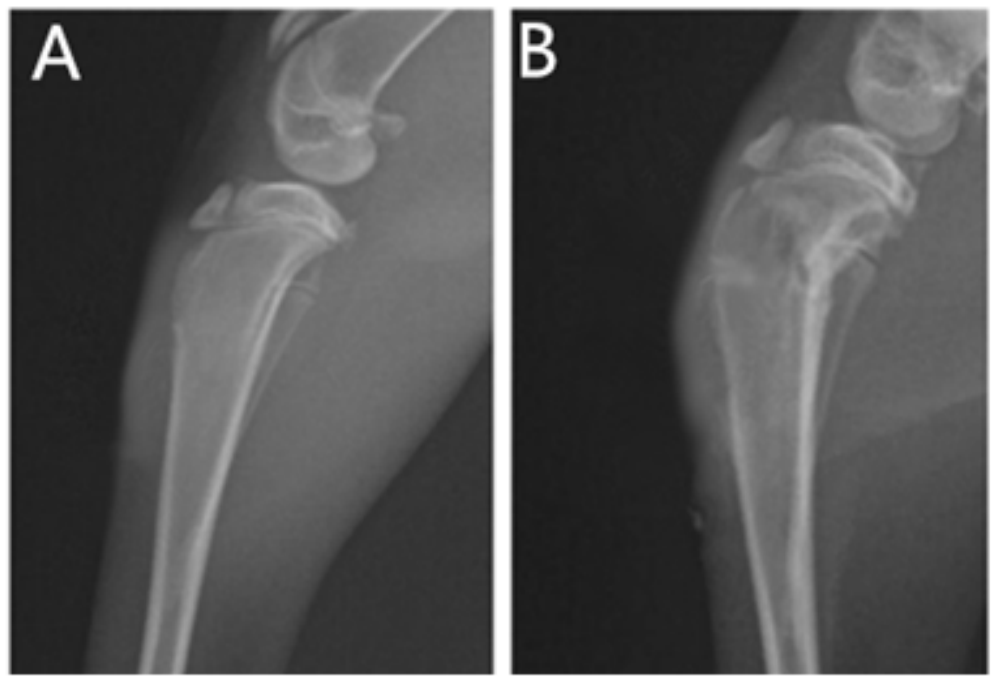

Figure 8

X-ray films 8 weeks after surgery in the (A) control and (B) experimental groups.

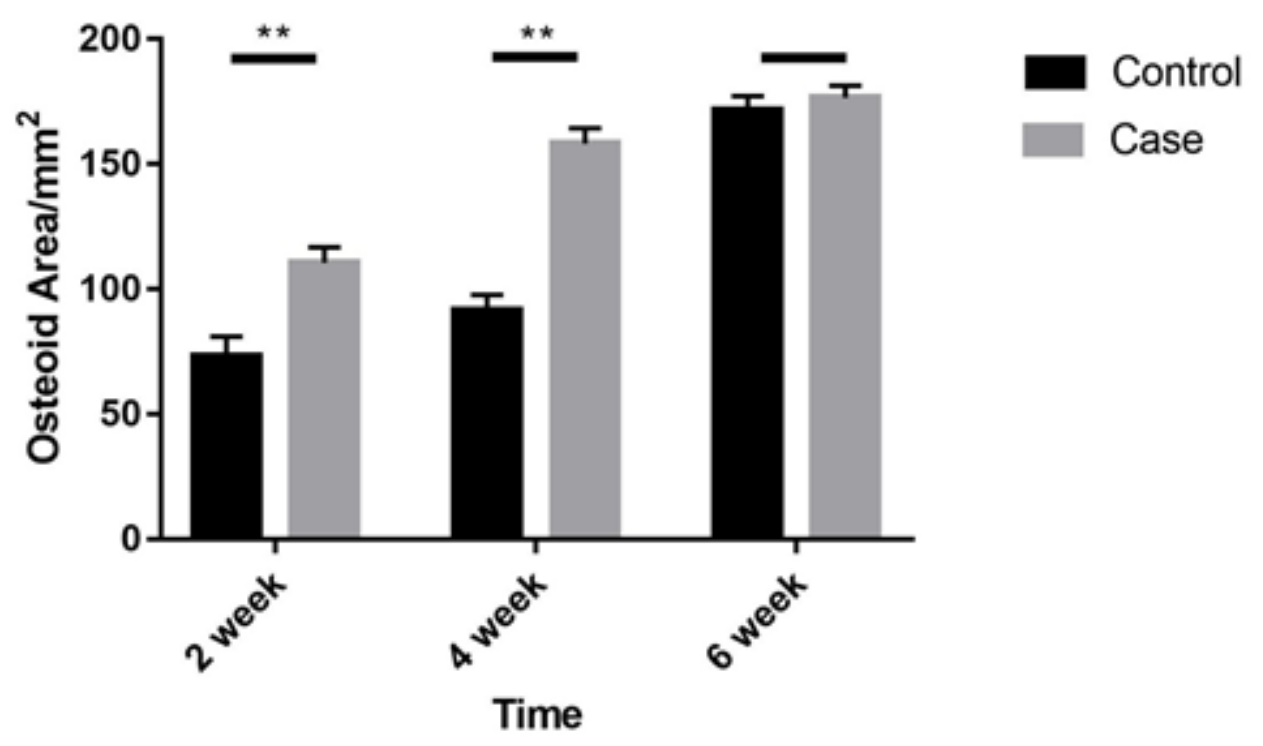

Figure 9

Osteophyte areas in experimental and control group rabbits 2, 4, and 6 weeks after surgery. 


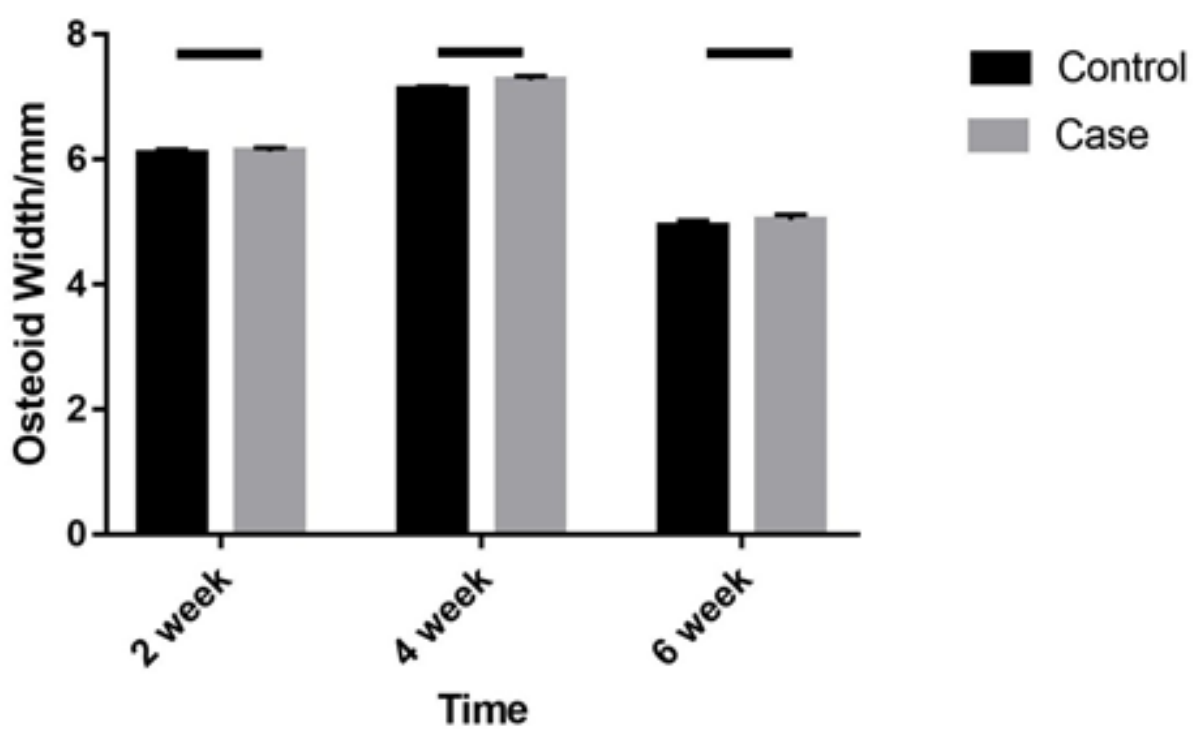

Figure 10

Epiphysis width in experimental and control group rabbits 2, 4, and 6 weeks after surgery.

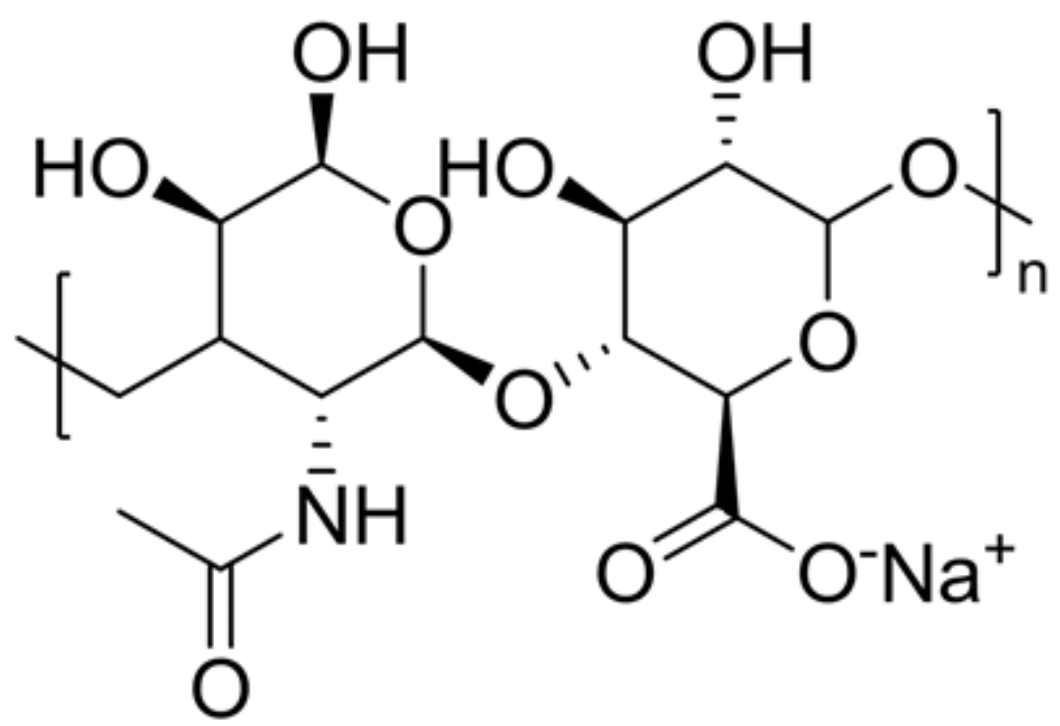

Figure 11

Structure of hyaluronic acid

\section{Supplementary Files}

This is a list of supplementary files associated with this preprint. Click to download.

- NC3RsARRIVEGuidelinesChecklistfillable.pdf 